\title{
A Report on the Bridges Seoul 2014 Conference
}

\author{
Reza Sarhangi
}

Published online: 8 January 2015

(C) Kim Williams Books, Turin 2014

\begin{abstract}
The International Conference of Bridges Seoul 2014 was the seventeenth annual conference in the Bridges series, which was held at the Gwacheon National Science Museum, Seoul, Korea, 14-19 August 2014. This year's conference brought approximately three hundred mathematicians, architects, scientists, artists, educators, musicians, writers, computer scientists, sculptures, dancers, weavers, and model builders together. In addition, for this year, thanks to the 2014 International Congress of Mathematicians (ICM) in Seoul, many participants from this congress attended Bridges. The list of participants also included about one thousand Korean students and their families, who were invited by the Gwacheon National Science Museum.
\end{abstract}

Keywords Report · Conference $\cdot$ Mathematics · Art

The International Conference of Bridges Seoul 2014 was the 17th annual conference in the Bridges series, which was held at the Gwacheon National Science Museum, Seoul, Korea, 14-19 August 2014.

This year's conference brought approximately three hundred mathematicians, architects, scientists, artists, educators, musicians, writers, computer scientists, sculptures, dancers, weavers, and model builders together. In addition, for this year, thanks to the 2014 International Congress of Mathematicians (ICM) in Seoul, many participants from this congress attended Bridges. The list of participants also included about one thousand Korean students and their families, who were invited by the Gwacheon National Science Museum. They enjoyed visiting many exhibitions at the conference (Figs. 1,2).

\footnotetext{
R. Sarhangi $(\square)$

Department of Mathematics, Towson University, Towson, MD, USA

e-mail: rsarhangi@towson.edu
} 


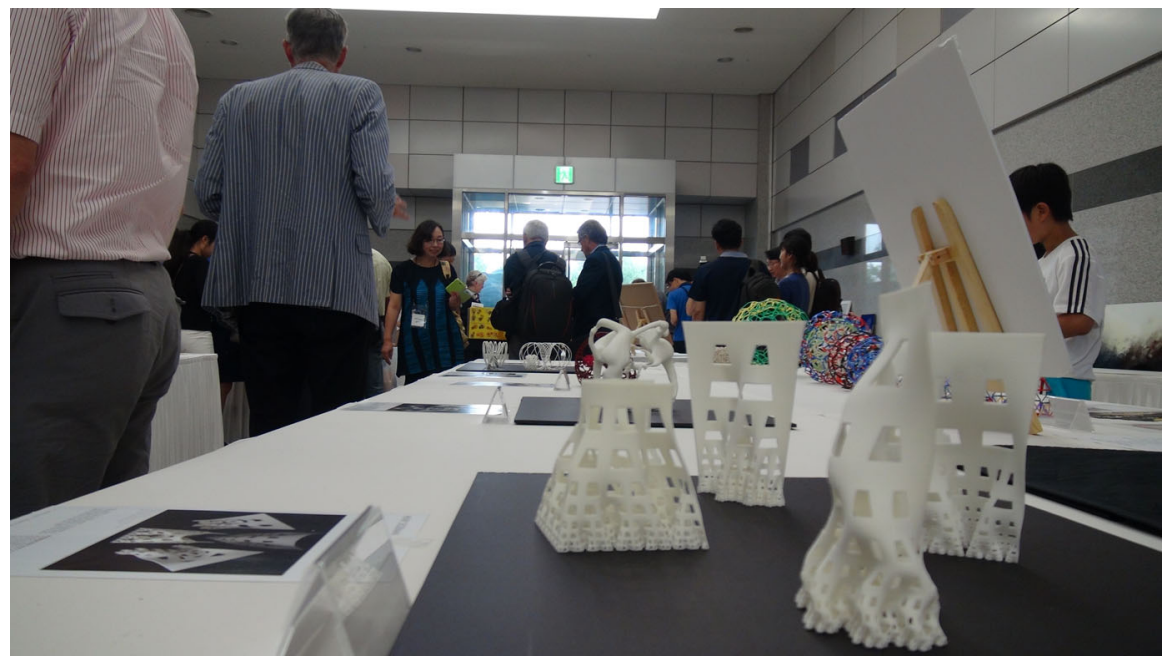

Fig. 1 Bridges art exhibition

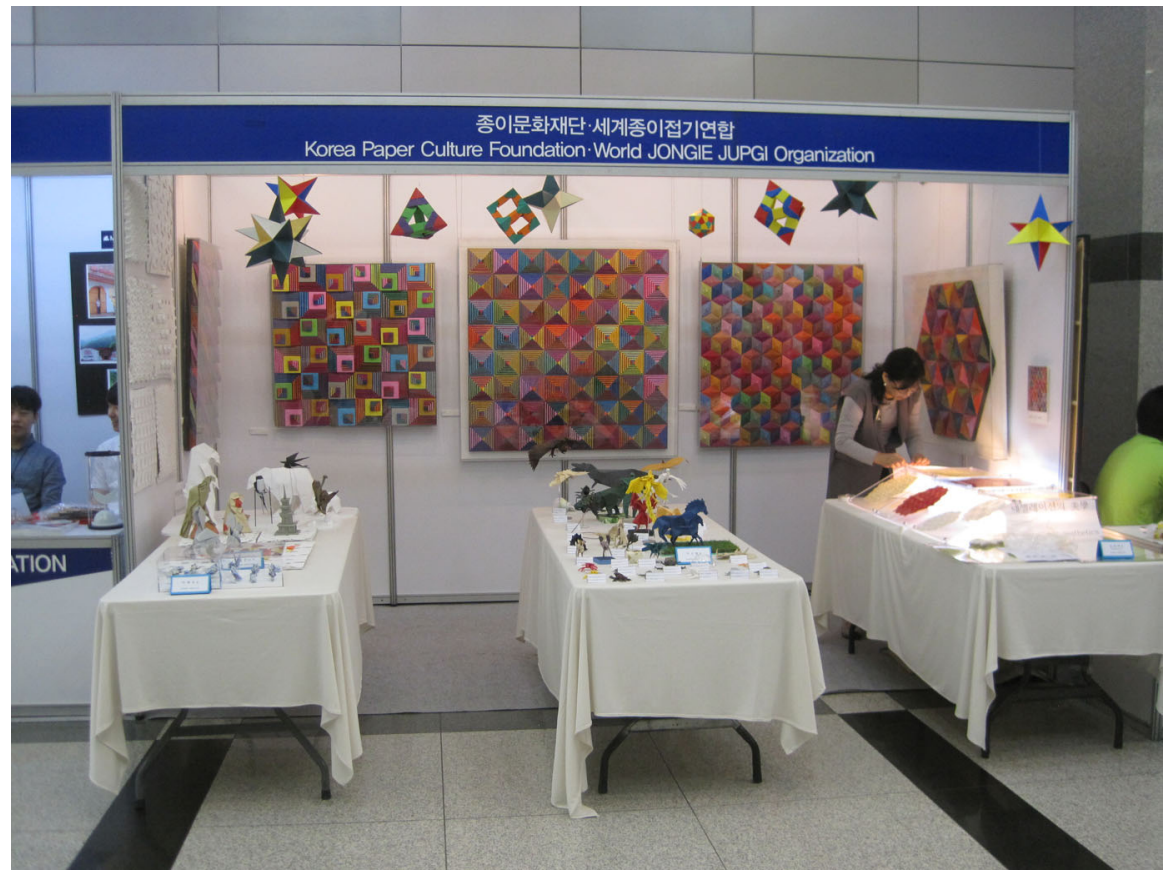

Fig. 2 Bridges Seoul exhibition

This year, the conference built its longest "bridge" yet, making its way to Asia for the first time, after many travels across North America and Europe, looking for opportunities to interact with new communities of participants. Such bridges foster 


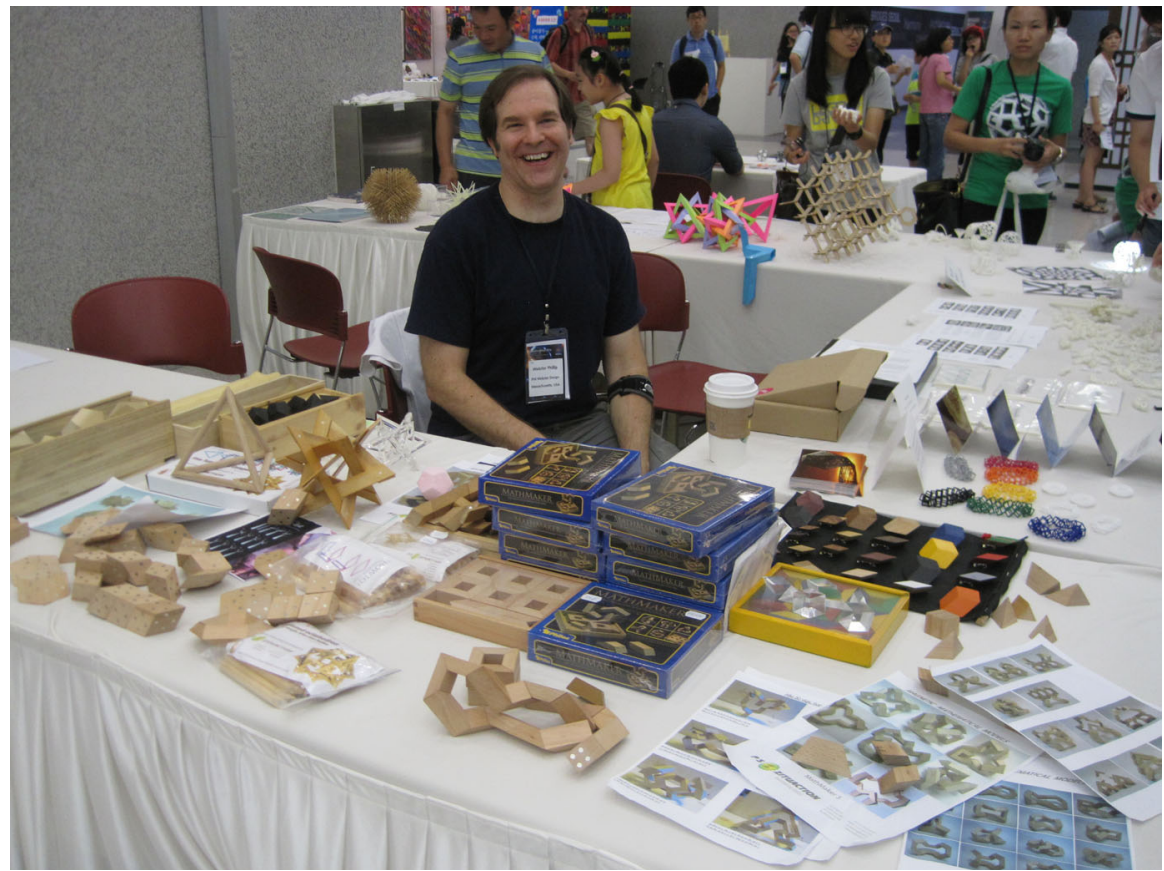

Fig. 3 Bridges show-and-tell area

excitement about art and mathematics by engaging with new groups of educators, artist, and the public (Figs. 3, 4).

The conference was held at Seoul thanks to Professor Ingrid Daubechies, President of the International Mathematical Union, who suggested holding Bridges

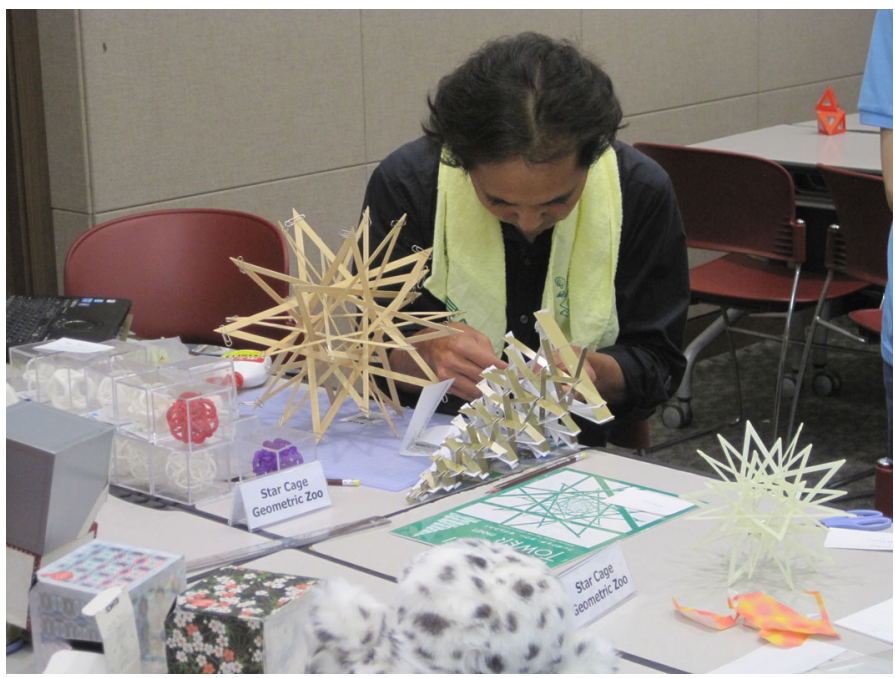

Fig. 4 Bridges art-in-progress area 


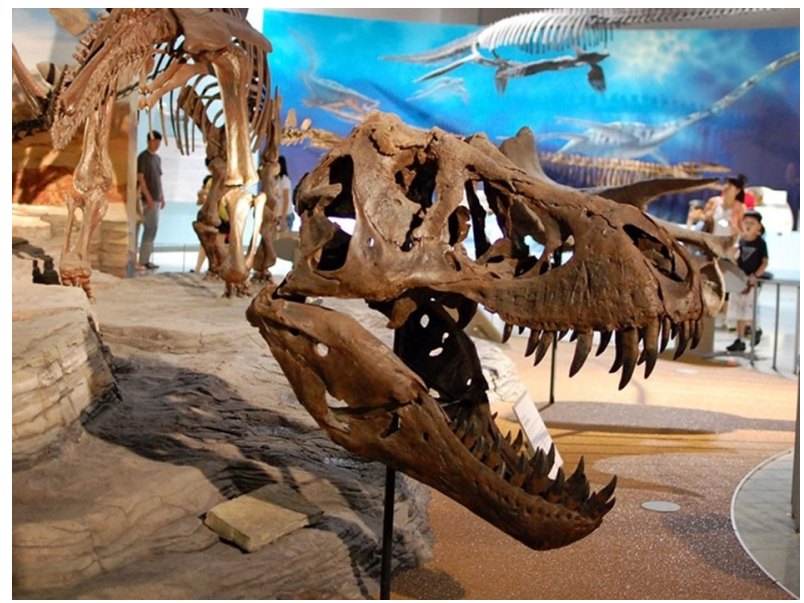

Fig. 5 Gwacheon National Science Museum

in Seoul as a satellite conference to the 2014 International Congress of Mathematicians (Seoul ICM 2014) and initiated the contact between the Bridges Organization, the ICM, and the Gwacheon National Science Museum. Based on several site visits and a series of meetings with the Gwacheon Museum Board of Directors and ICM organizers, Bridges assembled an international committee to make this conference a reality.

The Gwacheon National Science Museum, which opened its doors in 2008, is the largest science museum in Asia, and one of the largest in the world. Through its highly interactive exhibits and permanent collections, it strives to communicate scientific knowledge to a broad audience in an accessible way. Bridges is naturally aligned with this point of view-from the beginning, the conference has explored how to use art to talk about mathematics and aid the acquisition and retention of mathematical ideas. Conversely, Bridges was pleased to observe that the museum's vision statement demands that exhibitions be founded upon STEAM (Science, Technology, Engineering, Art, Mathematics), and not just STEM (Figs. 5, 6).

The Bridges Organization's educational goals were clearer than ever this year, as the organization simultaneously inaugurated MoSAIC (Mathematics of Science, Art, Industry, Culture), a series of mathematical art mini-conferences sponsored by the Mathematical Sciences Research Institute (MSRI). MSRI is one of the world's preeminent organizations for collaborative research. MoSAIC events can be organized anywhere, and funding is available for guest speakers and hands-on workshops (http:// www.MosaicMathArt.org). The Bridges Public Lecture Event for this year, which was also sponsored by MSRI, was led by Professor Noam D. Elkies, Department of Mathematics, Harvard University. The lecture was about the musical canon, which along with his piano performance, was illustrated with diagrams as well as a variety of musical examples that included a few improvisations in real time (Fig. 7).

Mathematics, art, architecture, and science all date far back to the prehistory of mankind and have in common that they involve abstractions from observations of 


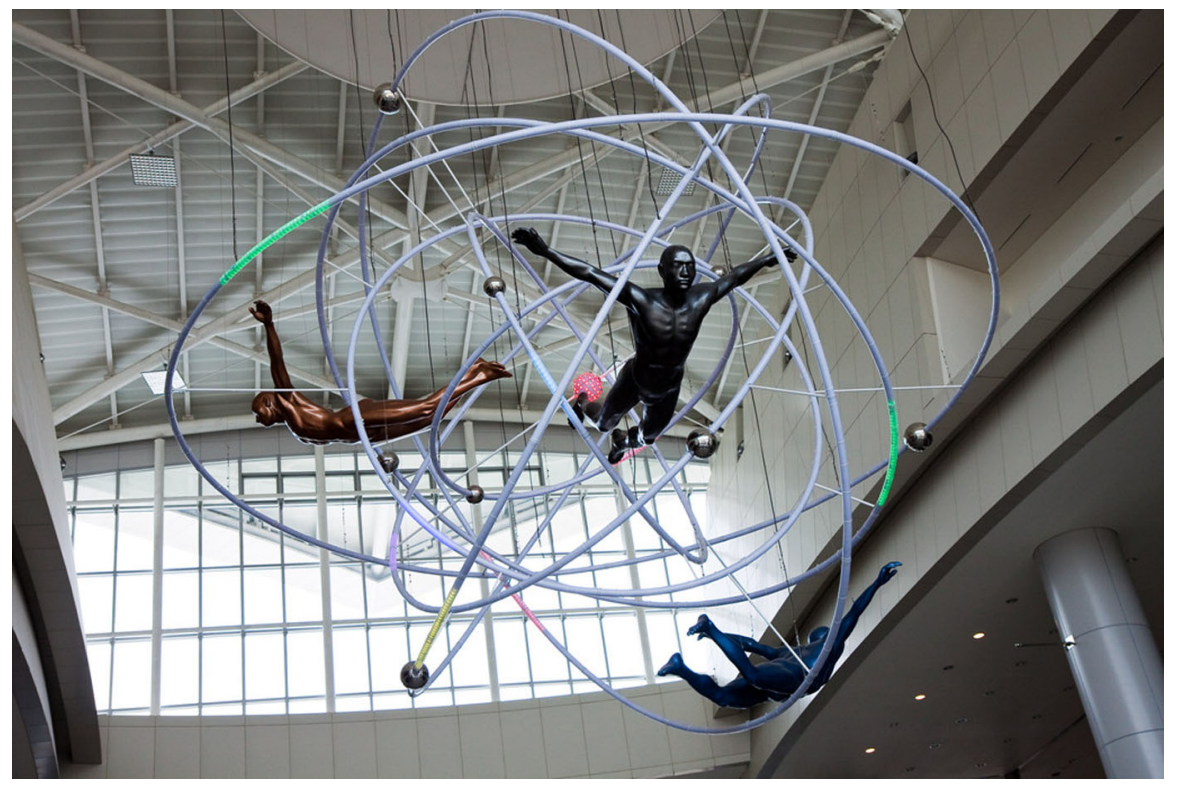

Fig. 6 Gwacheon National Science Museum

\section{MSRI $\square$ B Bridges Public Lecture}

Sponsored by Mathematical Sciences Research Institute (MSRI)
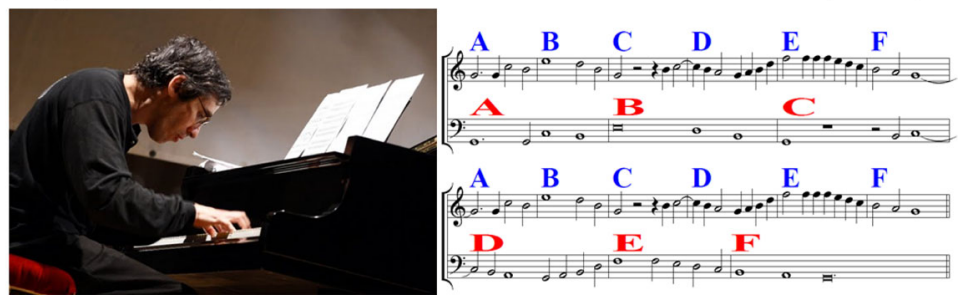

Fig. 7 Professor Noam D. Elkies at the MSRI public lecture

nature. Various types of patterns and structures naturally arise in these fields. It is a central theme of Bridges conference papers to elucidate and depict such structures, so this year's setting in the Science Museum created a particularly appropriate environment in which to ponder the roots of the structures found in math, art, architecture, and science. This year's Program Committee Chair was Gary Greenfield, University of Richmond, Virginia, with George Hart, Stony Brook University, New York, and Reza Sarhangi, Towson University, Maryland, serving as co-editors of the proceedings. Under Gary's direction, a committee comprising more than forty individuals from around the world provided reviews to submissions in three categories-regular papers, short papers, and workshop papers-and 
offered further feedback and advice to authors of accepted papers in order to improve their final versions. This process ultimately yielded the 37 regular papers, 44 short papers, and 8 workshop papers that are included in the printed Proceedings. The editors acknowledged the reviewing efforts of Mara Alagic, Wichita State University; Kansas, Bob Bosch, Oberlin College, Ohio; Paul Gailiunas, Newcastle, England; Craig S. Kaplan, University of Waterloo, Ontario, Canada; Douglas M. McKenna, Mathemaesthetics, Inc., Boulder, Colorado; and Carlo Séquin, UC Berkeley, who provided extra support (Figs. 8, 9).

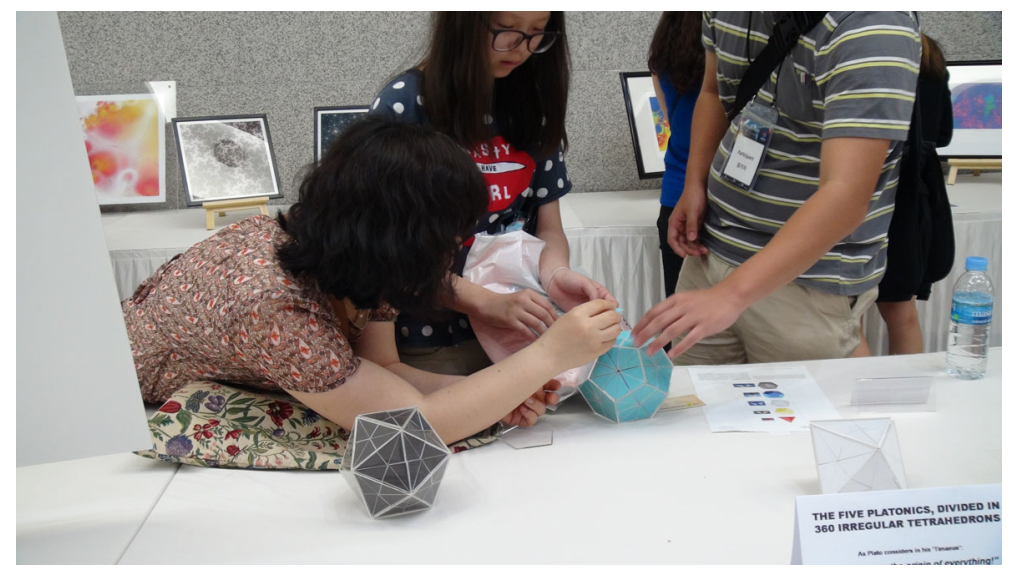

Fig. 8 Bridges art-in-progress area

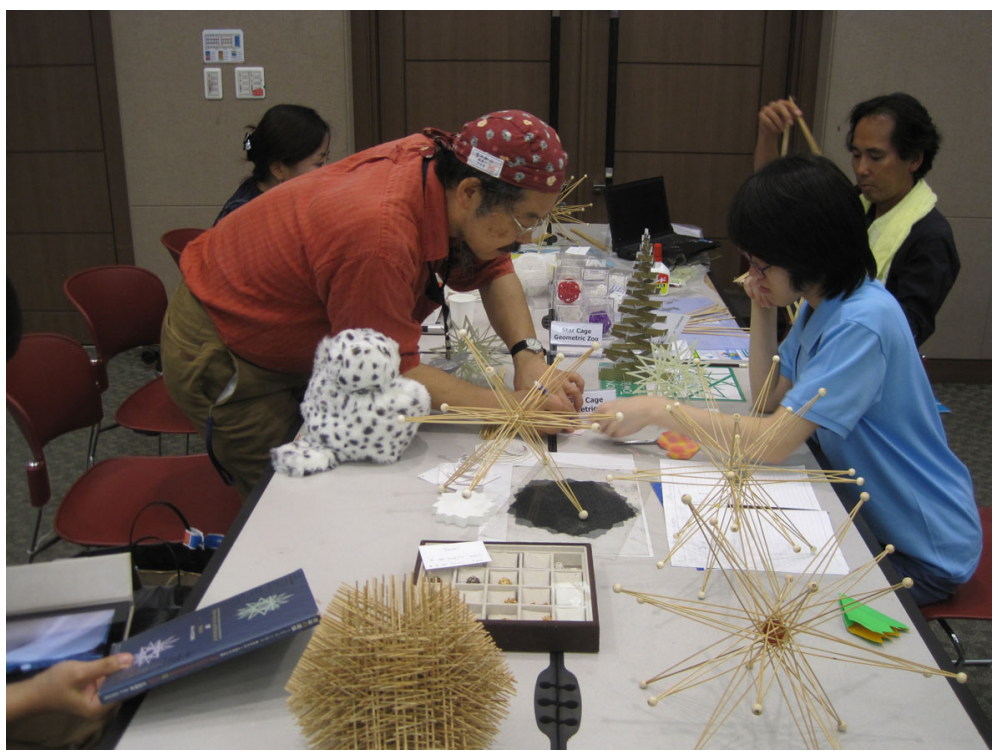

Fig. 9 Bridges art-in-progress area 
Many articles presented at the conference addressed different aspects of architectural structures and their relationships with mathematics. To name a few: Chamberlain Fong, San Francisco, California, presented "An Indoor Alternative to Stereographic Spherical Panoramas"; George Hart, Stony Brook University, presented "Geometry Ascending a Staircase"; the title of a talk by Tiffany Inglis, Technical University of Munich, Germany, was "Constructing Drawings of Impossible Figures with Axonometric Blocks and Pseudo-3D Manipulations"; "The Design of a Reconfigurable Maze" was a presentation by Craig S. Kaplan; Mahsa Kharazmi, Department of Art and Architecture, Tarbiat Modares University, Iran, and Reza Sarhangi presented "Geometric Study of Architectural Designs on a Twelfth Century Structure"; "The Kinochoron: A Manipulable Wire Model of the 16-cell" was a presentation by Taneli Luotoniemi, Aalto University, School of Arts, Design and Architecture, Helsinki, Finland; and Carlo H. Séquin and Michelle Galemmo, UC Berekely, presented "LEGO Knots".

An exhibition of mathematical art has been an annual feature of Bridges since 2001, and well over 100 artists contributed to this year's art exhibition. The list of contributors included several newcomers from Japan, South Korea, and China, as well as artists from North and South America, Europe, Africa, and Australia. A wide variety of artistic media was represented in the exhibition, including $2 \mathrm{D}$ and $3 \mathrm{D}$ digital prints, painting, beadwork, ceramics, wood, metal, quilting, and paper folding. Artists drew inspiration from the mathematics of fractals, polyhedra, nonEuclidean and four-dimensional geometry, tiling, knot theory, magic squares, and more. This year Katie McCallum, Brighton, UK, joined Robert Fathauer, Tessellations Company, Phoenix, Arizona, as co-curators of the exhibition. Robert Fathauer and Conan Chadbourne, San Antonio, Texas, edited the print catalog. Joining Robert and Katie on the jury were Anne Burns, Long Island University, New York, Nat Friedman, University at Albany, and Chaesoon Kwon, Gwacheon National Science Museum (Figs. 10, 11).

The Invited Plenary Speakers included Minhyong Kim, a professor from the University of Oxford, UK; the 2010 Fields Medalist Cédric Villani from Lyon University who directs the Institute Henri Poincaré in Paris; Thomas F. Banchoff,

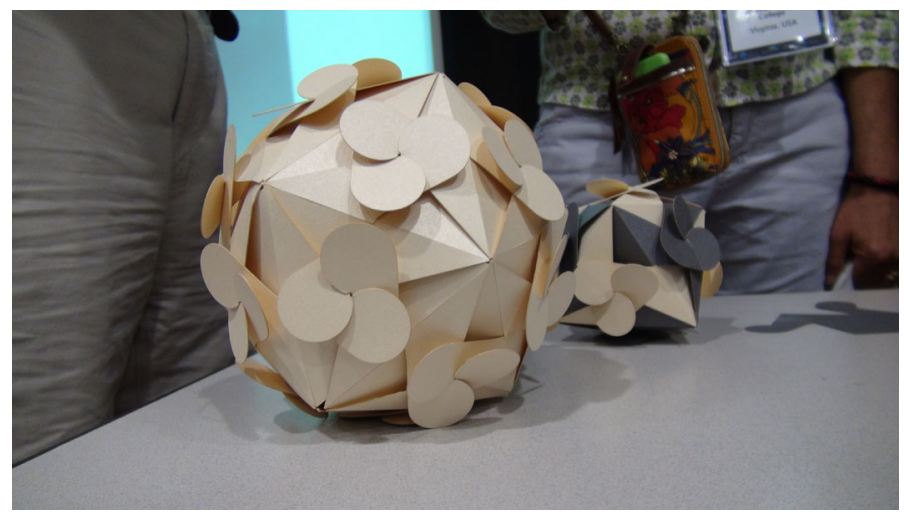

Fig. 10 Bridges art exhibition 


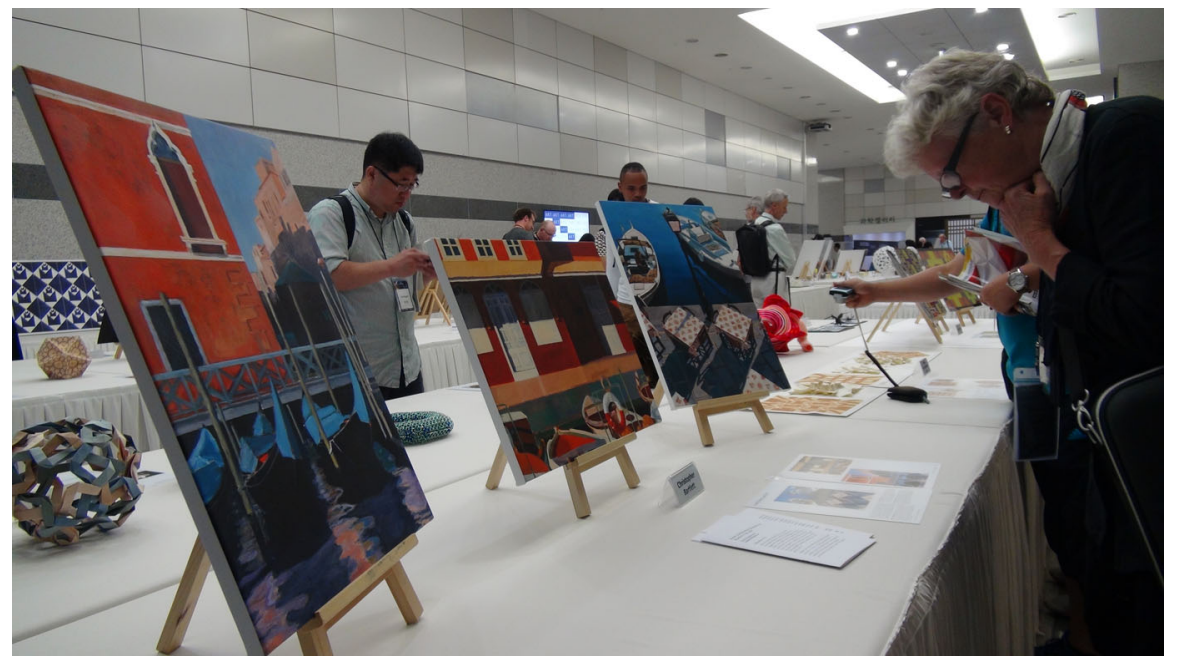

Fig. 11 Bridges art exhibition

the former President of the Mathematical Association of America (MAA), who is a professor at Brown University; Hinke M. Osinga and Bernd Krauskopf, Professors of Applied Mathematics at The University of Auckland, New Zealand; and the former American Mathematics Society (AMS) Vice President Frank Morgan from Williams College, whose proof with colleagues and students of the Double Bubble Conjecture was featured at NSF Discoveries (Fig. 12).

More artists and educators than ever are using movies, videos, and animations for education, industry, and art. A relatively new venue in this regard is the Bridges Short Movie Festival. The 5th Annual Bridges Short Movie Festival for this year
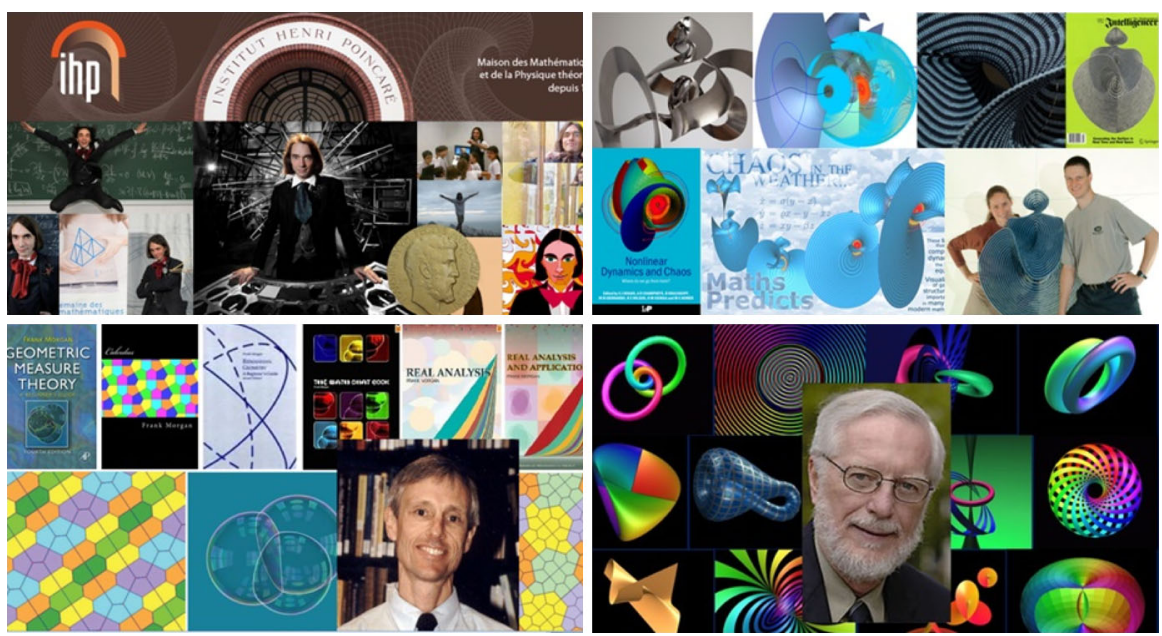

Fig. 12 Some of the invited plenary speakers: Cedric Villani, Hinke M. Osinga, Bernd Krauskopf, Frank Morgan, and Thomas F. Banchoff 


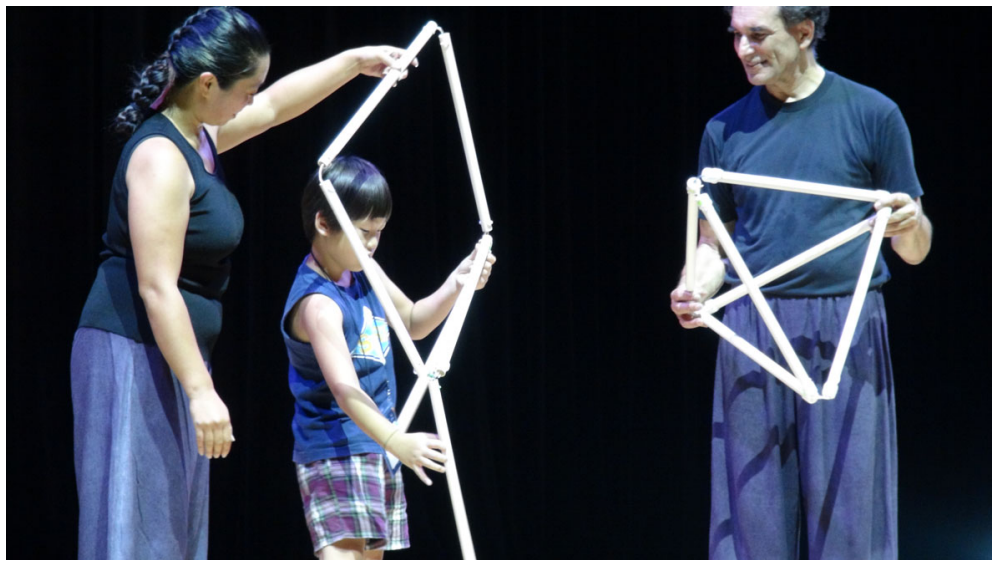

Fig. 13 Dance and mathematics theater

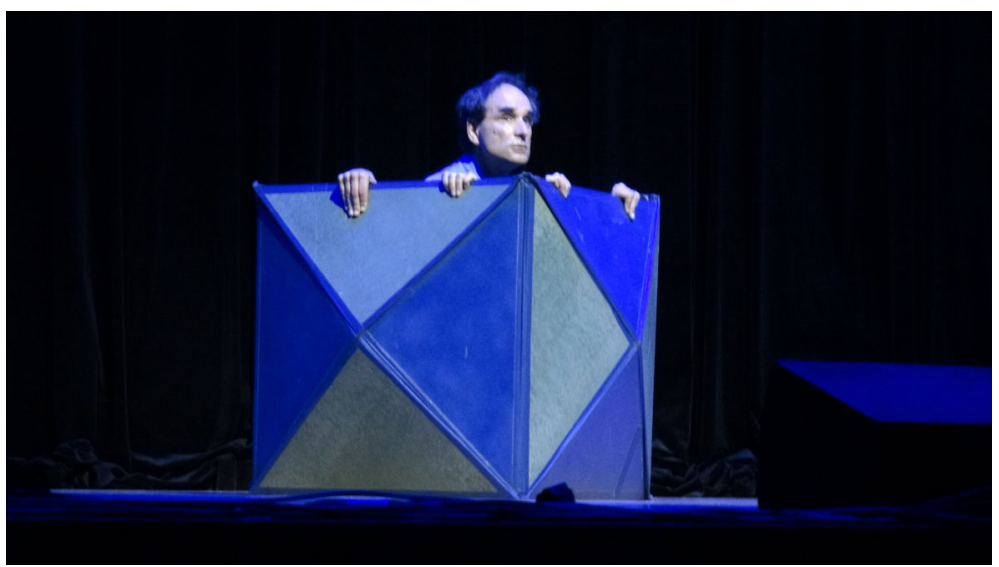

Fig. 14 Dance and mathematics theater

included a variety of juried and curated videos and short films. The program included movies, videos and animations that have been created for educational, corporate and artistic purposes, and provided another opportunity to experience innovative and integrative techniques in the fields of mathematics and art. The Bridges Short Movie Festival was coordinated by award-winning artist and author, Robert Bosch, a Professor of Mathematics at Oberlin College, Ohio.

Karl Schaffer, De Anza College, California, and Erik Stern, Weber State University, Utah, revealed many mathematics and art connections during their dance performance, through engaging choreography peppered with humor and entertaining audience interactions. Under their direction the Dr. Schaffer and Mr. Stern Dance Ensemble has appeared at many prestigious venues around the world. "Signs of Discovery" was the name of the show that Karl Schaffer and Erik Stern, along with Saki, California, prepared and presented at the conference (Figs. 13, 14). 


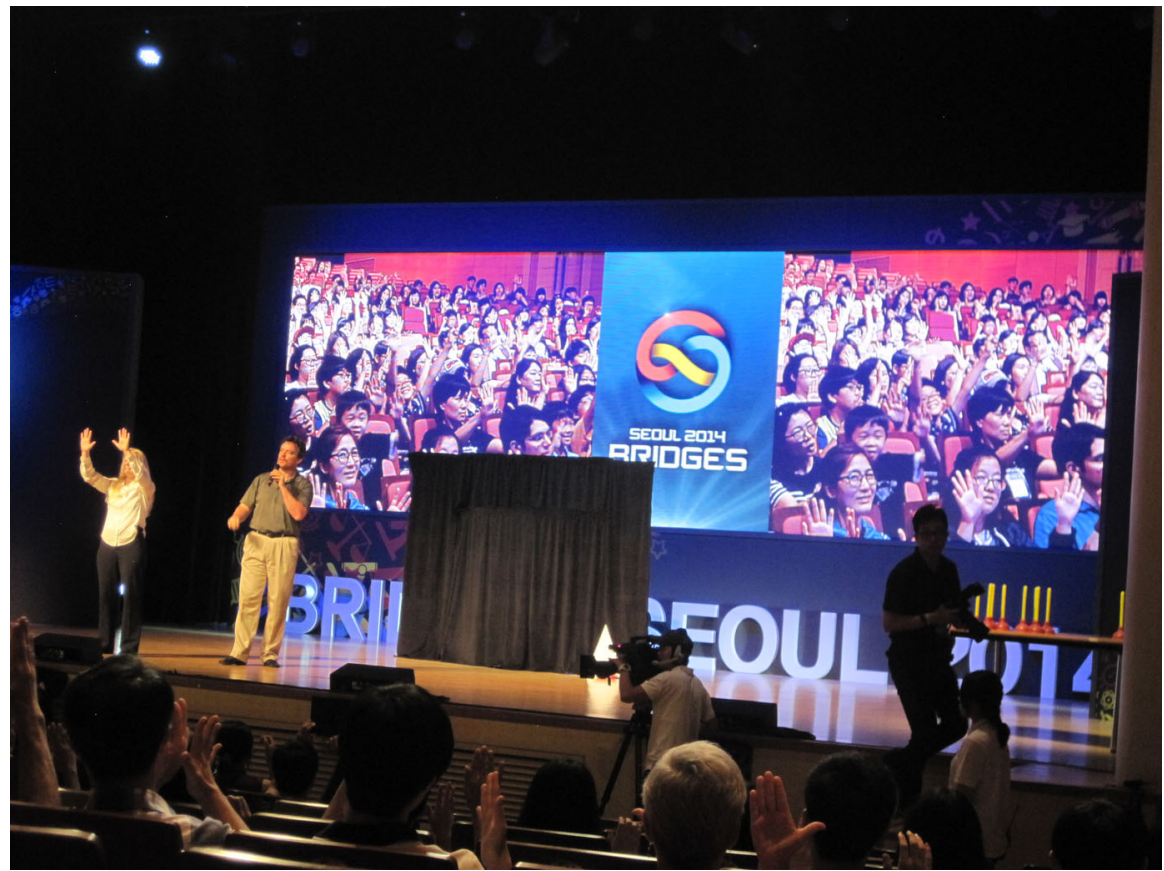

Fig. 15 Mime mathematics theater

Another highlight of the Bridges Conference, that in fact, was a gift to many public students and their families who participated in the Bridges Family Day event, was a Mime-Matics program: a show that combined mathematics with the art of mime. Dr. Tim Chartier, a professor of mathematics at Davidson College, North Carolina, along with his wife, Tanya Chartier, who has taught theater, have been trained at Le Centre du Silence mime school, the Dell'Arte International School of Physical Theater and with the world-renowned mime artist Marcel Marceau. Tim and Tanya Chartier's mime combines masks, puppetry, and classical mime illusions into a distinctive style that they have performed throughout the United States and in international settings. Their mime theater was very well received by the audiences. This performance was supported partially by MAA (The Mathematical Association of America) (Figs. 15, 16).

In addition to the dance and mime programs there were many other interesting events and workshop performances that offered activities to immerse the participants into the fun world of mathematics and the arts. There were many interesting community activities, games, workshops, interactive demonstrations, and presentations during this day. The Family Day project was coordinated by Kristóf Fenyvesi, Jyväskylä University, Finland (Figs. 17, 18).

The Annual Zometool Giant Construction is a Bridges community event that is supported by Zometool Inc. During this event the participants work on a giant Zometool sculpture, on a walk-in basis, starting on the first day of the conference. The 


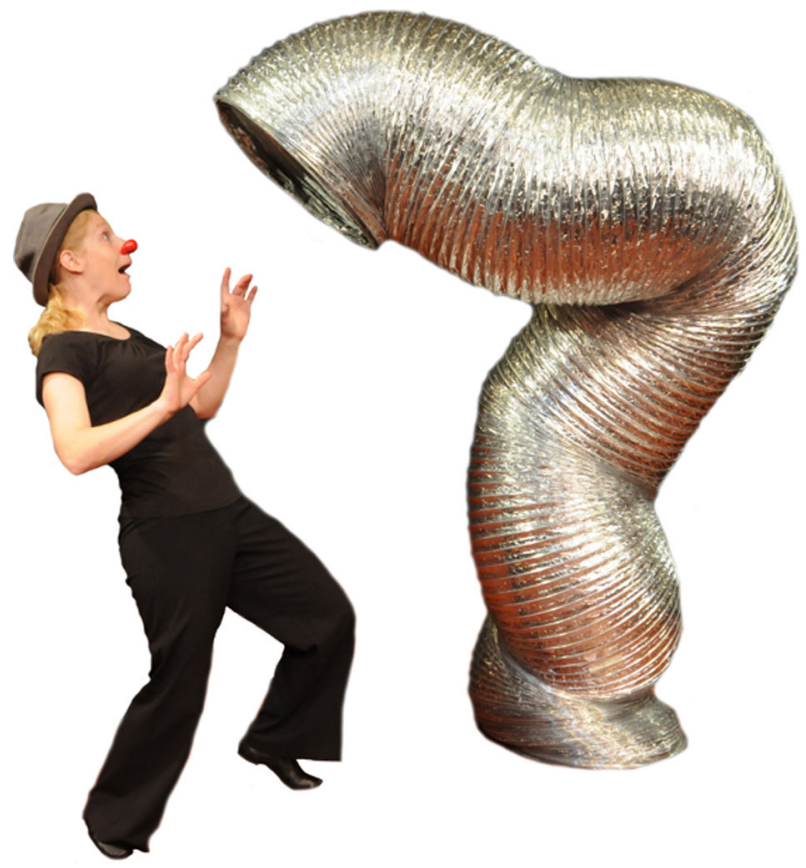

Fig. 16 Mime mathematics theater

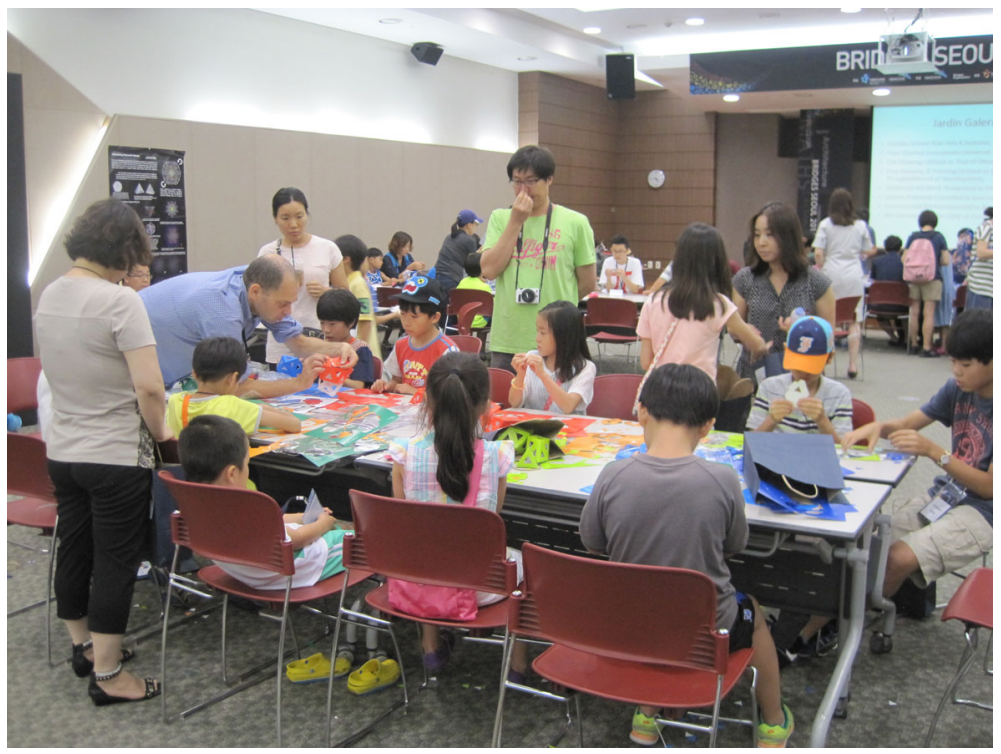

Fig. 17 Bridges family day 


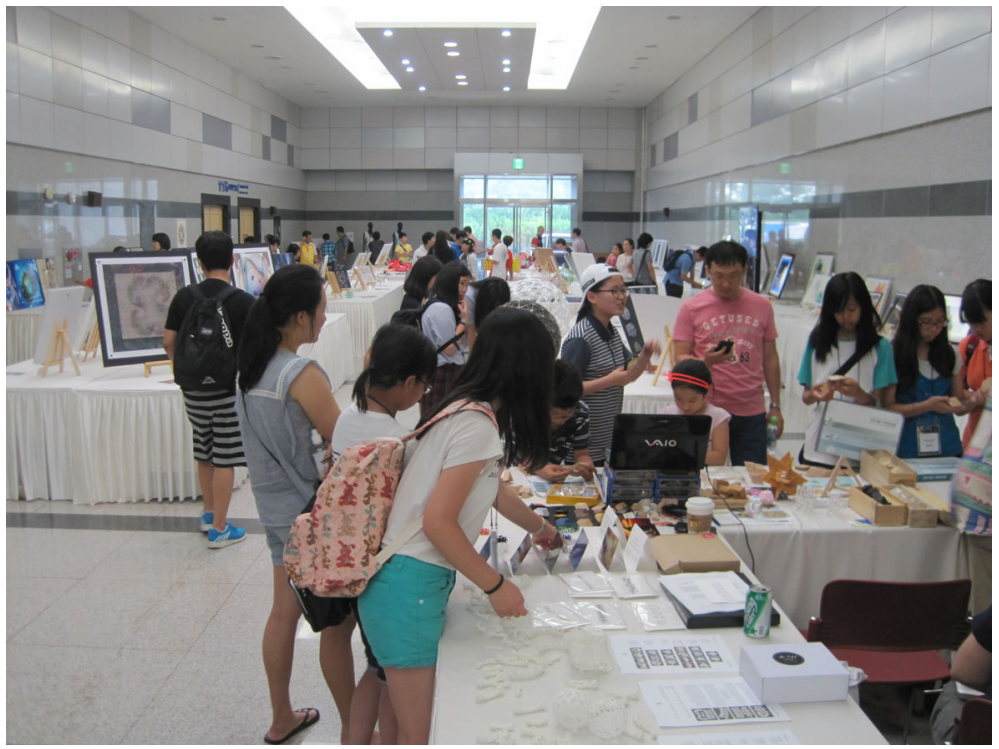

Fig. 18 Bridges family day

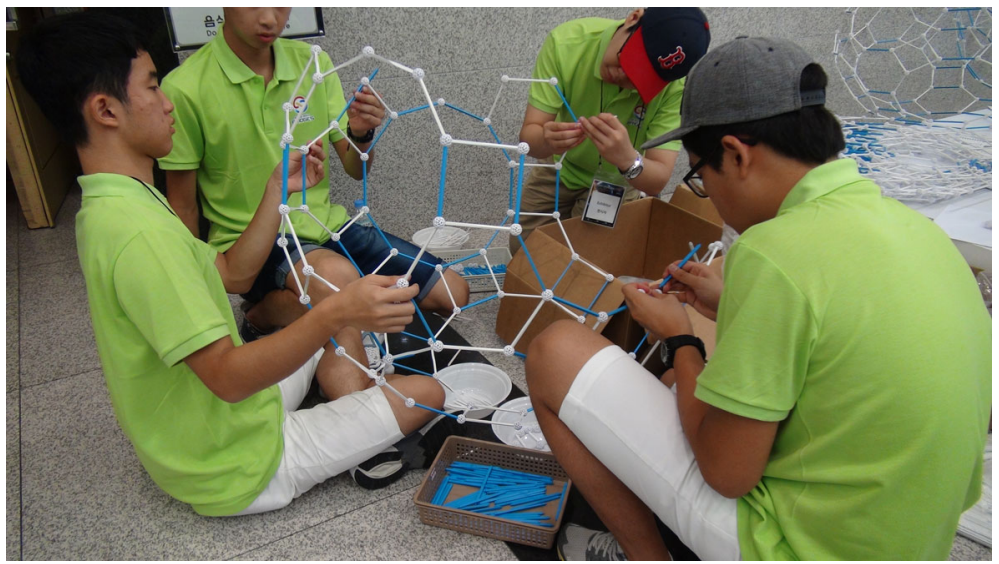

Fig. 19 Bridges Zometool sculpture project

2014 Zometool sculpture project attracted many participants, who were interested in architectural constructions. The Zome construction was an "Omnitruncated 120-Cell" consisting of over 20,000 plastic Zometool components (Figs. 19, 20).

The conference was concluded by a theater show on the evening of August 18, 2014. The goal of the theater event was to provide a spirited, engaging evening show that should be as rewarding to the audience as it is to the conference participants who volunteer as actors. The intersection between mathematics and theater has grown substantially in recent years, enough to become an area for scholarly research, but the main thrust of this event was to create an evening's 


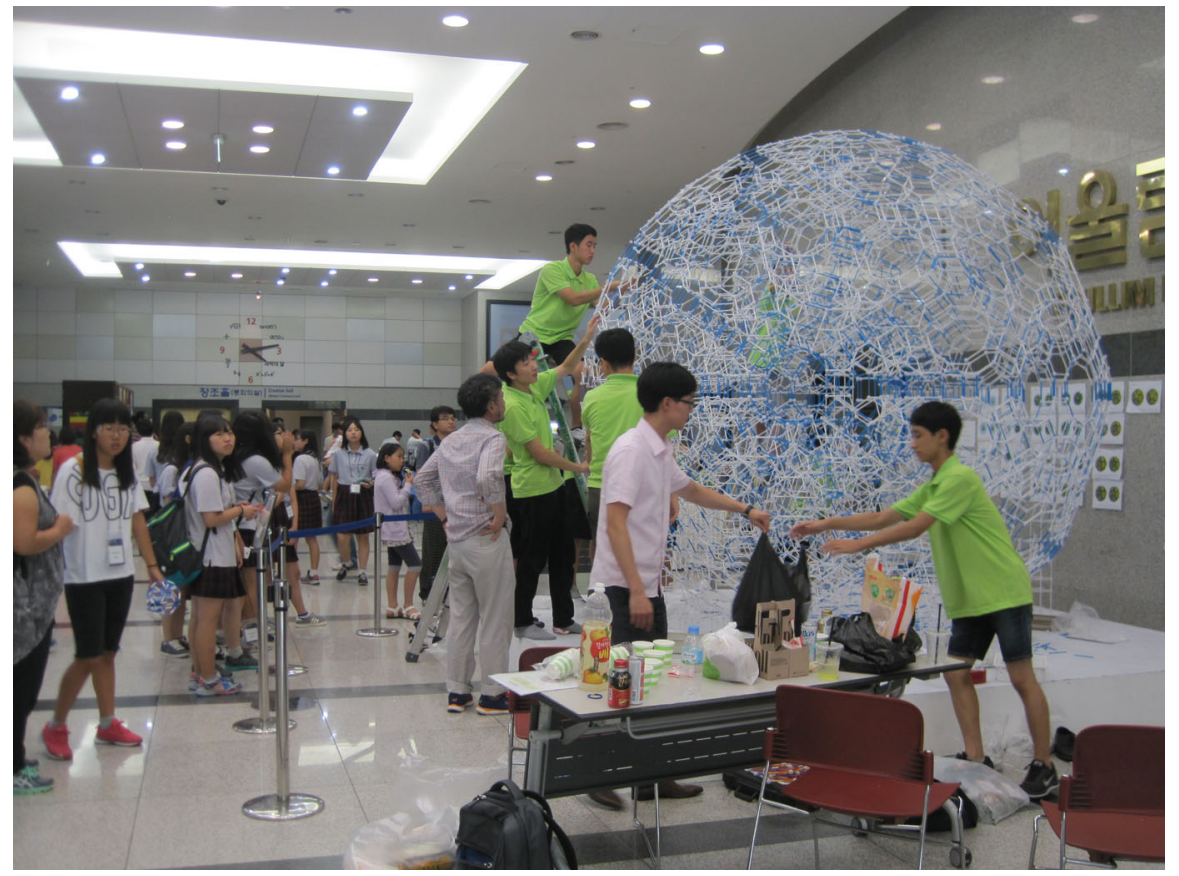

Fig. 20 Bridges Zometool sculpture project

entertainment consistent with the mathematics/art theme of Bridges. The theater event was lead by Steve Abbot, a mathematics professor at Middlebury College, Vermont. Steve Kennedy, from the Mathematics and Statistic Department of Carleton College, Minnesota, was the author of the script.

The next Bridges Conference, Bridges Baltimore 2015 (http://bridgesmathart. org/bridges-2015/), will be held at the University of Baltimore, Maryland, from 29 July to 1 August 2015.

The Bridges Seoul 2014 conference proceedings and the art exhibition catalog are available through the online store Math, Art, Fun http://mathartfun.com/ shopsite_sc/store/html/index.html. Moreover, there is an online repository of every paper ever published in the annual Bridges Conference, which is available via the open access Bridges Archive at http://archive.bridgesmathart.org/.

Reza Sarhangi is a professor of mathematics at Towson University, Maryland, USA. He teaches graduate courses in the study of patterns and mathematical designs, and supervises student research projects in this field. He is the founder and president of the Bridges Organization, which oversees the annual international conference series "Bridges: Mathematical Connections in Art, Music, and Science" (http://www. BridgesMathArt.Org). Sarhangi was a mathematics educator, graphic art designer, drama teacher, playwright, theater director, and scene designer in Iran before moving to the US in 1986. After completing a Ph.D. in Applied Mathematics (Control Theory) at Wichita State University, Kansas, he taught mathematics at Southwestern College in Winfield, Kansas. In 2000 he moved to Maryland and joined the faculty of Towson University. 